\title{
Evaluation of the Color Aesthetics of Fine Wood Based on Perceptual Cognition
}

\author{
$\mathrm{Na}$ Yu,* Jun Wang, Lian Hong, Beibei Tao, and Chong Zhang \\ In order to study the aesthetic preferences of individuals in terms of wood \\ color, the authors explored the preference for red sandalwood and wenge \\ wood of different hues and lightness values through a combination of an \\ eye movement technique and subjective evaluation. The experimental \\ results showed that: (1) sex factors had a significant effect on the eye \\ movement indexes in a modern aesthetic preference experiment; (2) the \\ preferences of the subjects varied slightly with different wood types but in \\ a lower range; and (3) the effective eye movement indexes in this study \\ were fixation duration, number of fixations, and number of last-sampling \\ positions; in addition, there were differences in the effective eye movement \\ indicators in different experiments. The subjects preferred a low lightness \\ value or color of the chair.
}

Keywords: Wood color preference; Hue; Lightness; Eye movement technique; Kansei cognition

Contact information: College of Furnishings and Industrial Design, Nanjing Forestry University, Nanjing 210037 P. R. China; *Corresponding author: yuna@njfu.edu.cn

\section{INTRODUCTION}

Wood, which is an excellent renewable material, has been widely used in the construction, home, and packaging industries due to its excellent natural properties. Nowadays, with the increased awareness of health and environmental protections, wood products, e.g., wood flooring, furniture, and boxes, are inseparable from the day to day lives of people. The visual impression is important in the perception of product quality, and the color is the most intuitive expression of visual properties. Therefore, it is important to determine the visual impression data of wood color.

Color is a phenomenon of human vision, and it is also a primary form of human access to information. In addition to giving people a visual aesthetic feeling, color also has profound importance in the cognition and emotion of individuals. Brogaard and Gatzia (2017) believe that the experience of color is related to factors of the cognitive system. Stone and English (1998) showed that different color environments in a workplace affected different levels of alertness in terms of work performance. Different colors have different effects on learning efficiency, i.e., the physiological and emotional states during learning (Ayash et al. 2016). Sutton and Altarriba (2016) pointed out that red is most often associated with negative emotions and emotionally loaded words, while yellow and white are associated with positive emotions and emotionally loaded words, respectively. In addition to the color itself, the hue, lightness, and saturation of a color stimulation also have a substantial correlation with the experiences of happiness, sadness, fear, and calm in an individual (Geslin et al. 2016). Color affects the aesthetic preferences and emotional psychology of an individual. Therefore, based on the emotional feeling of the user, the study of human visual physiological and psychological affects color review. Beauty preferences and exploring the psychological implications of the visual color hidden in the 
design can better establish a set of color application standards that meets the needs of people in the process of interactive design.

Recently, relevant research on wood color has focused the following topics: the effects of changes in color (Liu et al. 2017; Reinprecht et al. 2018) during wood aging, wood modifications including heat treatment (Aydemir et al. 2012), photodegradation (Timar et al. 2016), and impregnation (Zhang et al. 2010), as well as the aesthetic evaluation of the wood color itself. However, the study of wood color evaluation primarily has focused on the visual physical quantity of wood (Yang et al. 2012; He et al. 2016), the surface characteristics (Broman 2001), and its emotional characteristics (Broman 2001; Fujisaki et al. 2015). The point measurement method using a colorimeter or spectrometer is usually used to measure wood color (Varodi et al. 2017), while using the wood color calculation method to complete the transformation of the $L^{*}, a^{*}$, and $b^{*}$ in the $L^{*} a^{*} b^{*}$ space to the Munsell color space to find the corresponding wood color (Liu et al. 2013), and using the sense isometric method to study the relationship between the visual physical quantity and psychology (Liu et al. 1995). Few studies have quantitatively analyzed aesthetic preferences for wood color based on perceptual cognition to make it more accurately meet the perceptual needs of individuals. Therefore, it is extremely important to find an accurate way to evaluate the aesthetic preference of wood color.

Kansei engineering is used to quantify the feelings and needs of individuals, to use rational thinking to solve perceptual problems, to make qualitative and quantitative analysis of uncontrollable perceptual problems, and to make the original Kansei engineering needs of emptiness become rational and evidence-based. Currently, Kansei engineering is used not only in packaging and modeling design (Djatna and Kurniati 2015; Vieira et al. 2017), web design (Fu et al. 2016), and visual comfort evaluation (Korsavi et al. 2016; Buratti et al. 2018; Liu and Kang 2018), but it has also achieved many accomplishments in terms of the study of color aesthetics. Manav (2017) asked 170 color non-experts to match the most appropriate adjectives with a given street view to study urban color-emotional design color schemes. Hsiao and Yang (2016) used a questionnaire to select 10 product images and calculated a three-color harmonious aesthetic measurement based on aesthetic measurement theory to predict the color trend design system that meets market demands. Among them, the semantic differential (SD) method was one of the important methods used in Kansei engineering. A psychometric measurement was carried out through a language scale to obtain the perceptual cognition of the subject, and the basic data for the subsequent Kansei engineering analysis was constructed to determine the bias of the tester on "inductive demand" and is particularly applicable to color trend research. Shieh and Yeh (2015) used the SD method and preference evaluation questionnaire to investigate the aesthetic Kansei of the subject for the color of various sports shoes. Miyoshi et al. (2015) used the SD method to evaluate the best blue primary colors from four different blue colors (430 nm, $450 \mathrm{~nm}, 470 \mathrm{~nm}$, and $480 \mathrm{~nm}$ ) from the perspective of an inductive engineering evaluation. Tama et al. (2015) used the Kansei engineering SD method to measure the color emotion of each color scheme and obtain the color scheme that can represent the "inductive demand" and its application situation. Therefore, based on the study of color aesthetic preferences obtained in the study of perceptual engineering, it not only can satisfy the validity of scientific calculation, but also it can satisfy the perception of the subjective experiences of the individual.

Eye-tracking movement technology reflects the cognitive process and can predict the psychomotor performance. Currently, eye movement technology, through the quantitative analysis of physiological data, has been used not only in advertising evaluation 
(Xing and Qiang 2009), appearance design (Mamassian 2016), and interface design evaluation (Higa et al. 2006), but also in color research. Lee et al. (2013) used an eight natural color system (NCS) as stimuli to identify eye movement in experiments and eye movement indicators, e.g., gaze duration, and showed a correlation between gaze time and color preference ranking and eye movement patterns. Mirijovsky and Polpelka (2016) studied 24 subjects via an eye movement technique to find the most realistic and optimal color settings. Ho et al. (2015) explored the visual effects of different color assignments on subjective color preferences through eye tracking technology. The results showed that the average pupil size determined via eye movement indicators can effectively reflect the difference between color preference and visual comfort. Liu et al. (2015) analyzed the number of gazes and gaze duration of college students watching different wardrobe combinations through eye movement technology and indicated that subjects of this age group prefer samples with bright colors.

Previous studies usually have investigated the relationship between form and perceptual cognition or the relationship between morphology and eye movement. Traditional perceptual evaluation involves subjective assessment of the overall form, but it does not clarify the effects of different parts on the perceptual evaluation of the individual. The microscopic analysis of eye movements may make up for this defect in subjective evaluation. Hsu et al. (2017) had the subjects carry out eight SD evaluations for 16 chairs and used an eye movement tracking system to analyze the changes in the fixation points of the participants as they performed various perceptual assessments. A correlation between eye movements and perceptual evaluation was observed. Therefore, the authors combined the two methods to carry out the present research. Through eye movement experiments and a questionnaire survey, Choi et al. (2012) evaluated the effects of the attention of the consumer on the label information and discussed the effect of over-the-counter drug packaging design on consumer risk judgment. Köhler et al. (2014) hypothesized that by using eye movement tracking, the traditional Kansei engineering method can be extended to evaluate designs and to obtain objective data for customer product perception and evaluation. Muslim et al. (2013) studied the effects of four newspaper advertisement combinations via eye-movement techniques and questionnaires. The study found that color factors were effective in their experiment. Wang et al. (2018) combined eye tracking technology with subjective evaluation to study the visual perception of nine different cardboard products. Ho et al. (2015) explored the visual effects of different color assignments and subjective color preferences through eye tracking technology supplemented by questionnaires before and after testing. Jia and Niu (2017) studied the aesthetic characteristics of 22 kinds of wood commonly used in Ming style furniture through a combination of a questionnaire survey and an eye tracking test and explored the basic laws of the aesthetic trend of material color. This provided a basis for the author's quantitative study of the aesthetics of wood.

Hue is the primary characteristic of color and the most accurate standard to distinguish different colors. Lightness refers to the diffuse reflectance of the color. Kearney (1966) used a paired comparison method to determine the tone preferences of three different hue levels and three levels of lightness; the results showed that preference was influenced by the color phase and is not affected the lightness. Gong et al. (2017) used 18 words to study the correlation between color emotion and color preference from the aspects of color, chromaticity, and lightness, and found that color plays a more important role than color and lightness. Shamey et al. (2015) measured 56 normal subjects to evaluate approximately 27 different patches of gray color through psychophysical experiments. The 
results showed that the perception of a gray scale was affected by the hue. Therefore, this paper explores the effective eye movement index and aesthetic preference of the subjects in observing different wood colors in terms of hue and lightness. First, the objective physiological data of the visual cognition of the subjects were extracted via an eye movement technique. Then, the eye movement indexes were selected according to subjective evaluation, and the aesthetic preference of the subjects for different wood colors were judged in order to improve the color aesthetic evaluation and provide a more effective methodology.

\section{EXPERIMENTAL}

\section{Materials and Methods}

In this study, red sandalwood and wenge wood were used as the experimental materials. Red sandalwood has a fine and uniform texture, and the wood grain of wenge wood has clear of color and lightness.

This paper divides color and lightness into five grades and explores the aesthetic preference of modern people for fine wood colors by combining eye movement and subjective evaluation.

\section{Experimental subject}

The subjects were primarily college students, aged 22 years old to 25 years old, with good health and normal eyesight. The number of participants was 32, including 16 males and 16 females.

\section{Laboratory apparatus}

In this experiment, a Tobii 1750 eye movement tracker was used with the Clearview 2.70 program to record, analyze, and derive the eye movement index data during the experiment. The accuracy of the eye movement instrument was 0.5 degrees, and the sampling rate was $50 \mathrm{~Hz}$.

\section{Experimental materials}

The experimental materials were divided into pre-experimental materials and formal experimental materials. The pre-experimental materials were selected from two different shades of cabinets, as shown in Figs. 1 and 2. The official experimental materials used four images, obtained by toning the wood with two lightness values and two hue values, which were the lightness of red sandalwood, the hue group of red sandalwood, the lightness group of wenge wood, and the hue group of wenge wood (as shown in Figs. 3 to $6)$.

The two kinds of wood samples were scanned, and pictures of the wood grains were obtained. Then the wood images obtained were directly processed in Photoshop according to the measured value $(\mathrm{V})$, hue $(\mathrm{H})$, and saturation $(\mathrm{S})$ values of the wood color (the hue of sandalwood is $4.08 \mathrm{YR}$, the lightness is 1.81 , and the saturation is 11.03 ; the hue of wenge wood is $8.53 \mathrm{YR}$, the lightness is 2.74 , and the saturation is 6.57 ), which were used as the two basic images. The hue and lightness change thresholds of the two basic pictures were divided equally into five levels and attached to a Su-style chair; therefore, the five levels of pictures A, B, C, D, and E were obtained. In order to reduce the effects of the visual background on the observation of the picture, the five chairs were placed on a white 
background (1280 pixels x 1024 pixels), forming a large picture. To ensure that each chair in the larger picture appears the same number of times on the upper left, the five chairs were placed in turn at the top left position in the picture once in a row (the other modeling factors did not change). The specific changes in lightness and hue were as follows:
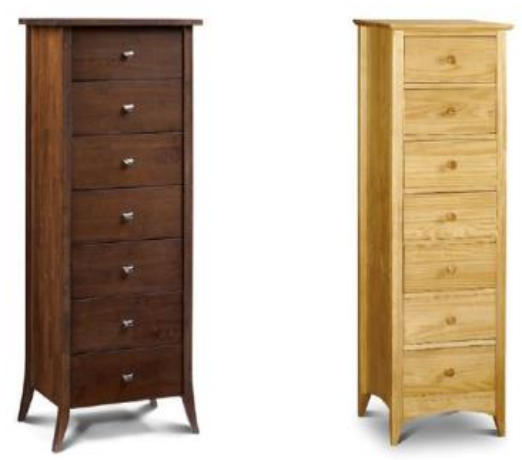

Fig. 1. Pre-experimental material
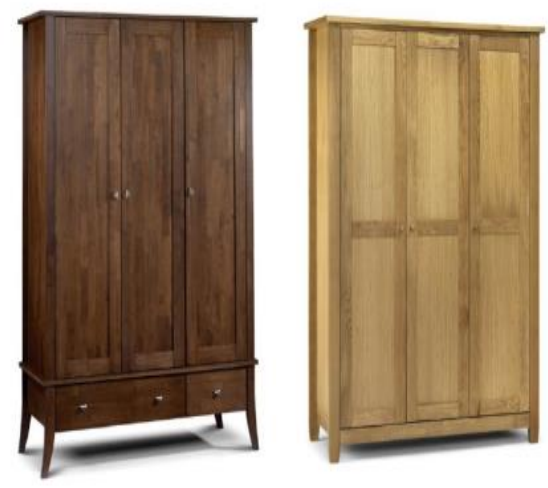

Fig. 2. Pre-experimental material

Lightness group (as shown in Fig. 3 and 4): each red sandalwood chair was labeled according to its lightness value. The chairs with a lightness value of 0 (the lightness of the original map was 1.81) were labeled $\mathrm{A}$, the chairs with a lightness value of -10 were labeled $\mathrm{B}$, the chairs with a lightness value of -5 were labeled $\mathrm{C}$, the chairs with a lightness value of 5 were labeled D, and the chairs with a lightness value of 10 were labeled $\mathrm{E}$. The labeling of the wenge wood chairs (the lightness of the original map was 2.74) followed the same protocols as the red sandalwood samples.

Hue group (as shown in Figs. 5 and 6): each red sandalwood chair was labeled according to its hue value. The chairs with a hue value of 0 (the hue of the original map was 4.08 YR) were labeled $A$, the chairs with a hue value of -10 were labeled $B$, the chairs with a hue value of -5 were labeled $C$, the chairs with a hue value of 5 were labeled $D$, and the chairs with a hue value of 10 were labeled E. The labeling of the wenge wood chairs (the lightness of the original map is $8.53 \mathrm{YR}$ ) followed the same protocols as the red sandalwood samples.

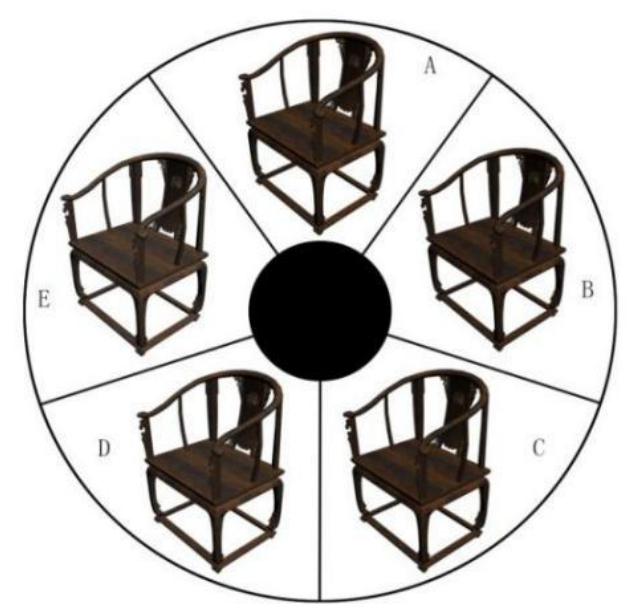

Fig. 3. The lightness values of red sandalwood. The lightness of the original map was 1.81 , and the values of $A, B, C, D$, and $E$ are $0,-10,-5,5$, and 10 , respectively, 


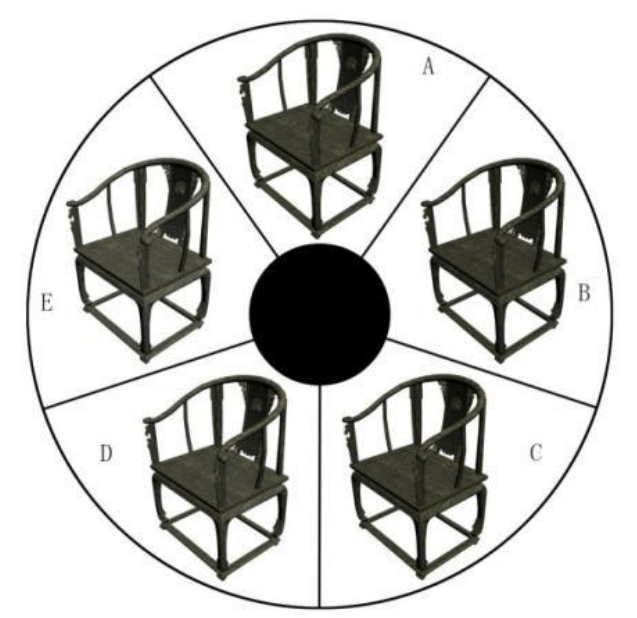

Fig. 4. The lightness values of wenge wood. The lightness of the original map was 2.74 , and the values of $A, B, C, D$, and $E$ are $0,-10,-5,5$, and 10 , respectively.

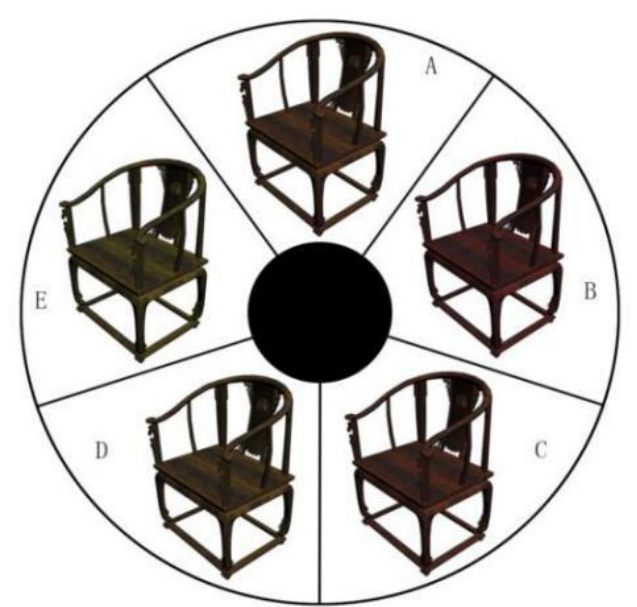

Fig. 5. The hue values of red sandalwood. The hue of the original map was $4.08 \mathrm{YR}$, and the values of $A, B, C, D$, and $E$ are $0,-10,-5,5$, and 10 , respectively.

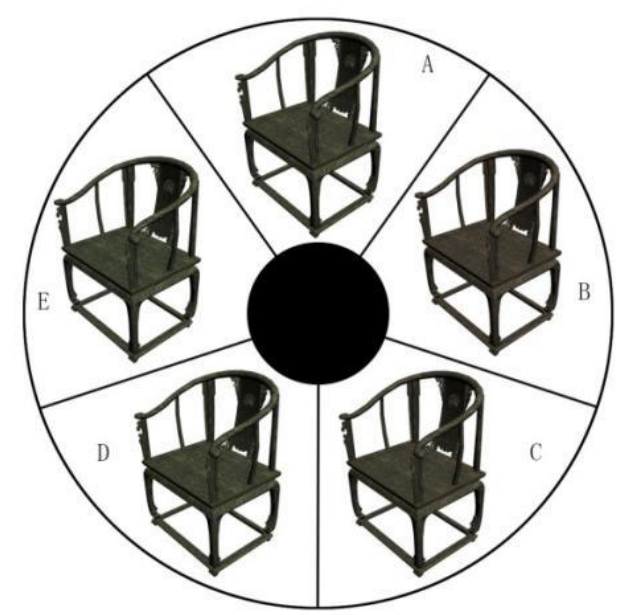

Fig. 6. The hue values of wenge wood. The hue of the original map was $8.53 \mathrm{YR}$, and the values of $A, B, C, D$, and $E$ are $0,-10,-5,5$, and 10 , respectively. 


\section{Experimental method}

This experiment included two parts: eye movement and subjective evaluation. The subjects first performed the eye movement examination and then filled out the questionnaire. The experiment was carried out individually, and a good experimental environment as well as proper light conditions were ensured during the experiment.

\section{Eye movement test}

(1) The subjects sat $80 \mathrm{~cm}$ from the eye movement monitor, and the posture of the subjects was adjusted so that the instrument captured the eye data successfully.

(2) Eye calibration: the subjects were guided to observe the position of 5 calibration points on the display screen in turn.

(3) The pre-experiment, which provided the two pictures of the cabinet bodies with different hues, was started.

(4) The first screen presented was the gaze point positioning picture, a white picture with a black cross in the middle, and the subject was asked to look at the cross for $2 \mathrm{~s}$, as the formal pre-experimental material (as shown in Figs. 1 and 2).

(5) When the experimental materials were presented, the eye tracker recorded the gaze of the subject, and the screen displayed the gaze point positioning image for $2 \mathrm{~s}$, and then the gaze point was re-corrected. After the correction was finished, new experimental materials appeared on the screen, and each experimental image was presented for $10 \mathrm{~s}$.

(6) According to the results of the pre-experiment, whether the subject fully understood the steps of the experiment was judged, and if the subject did not understand, then the pre-experiment was continued until the subject fully understood. If the subject understood, then a formal experiment was conducted. The four images in the formal experiment were presented in sequence as Powerpoint slides (Fig. 7), and each picture was presented for $10 \mathrm{~s}$, with the transition picture between the pictures to correct the fixation point being presented for $2 \mathrm{~s}$. Then, the process was repeated to complete the experiment.

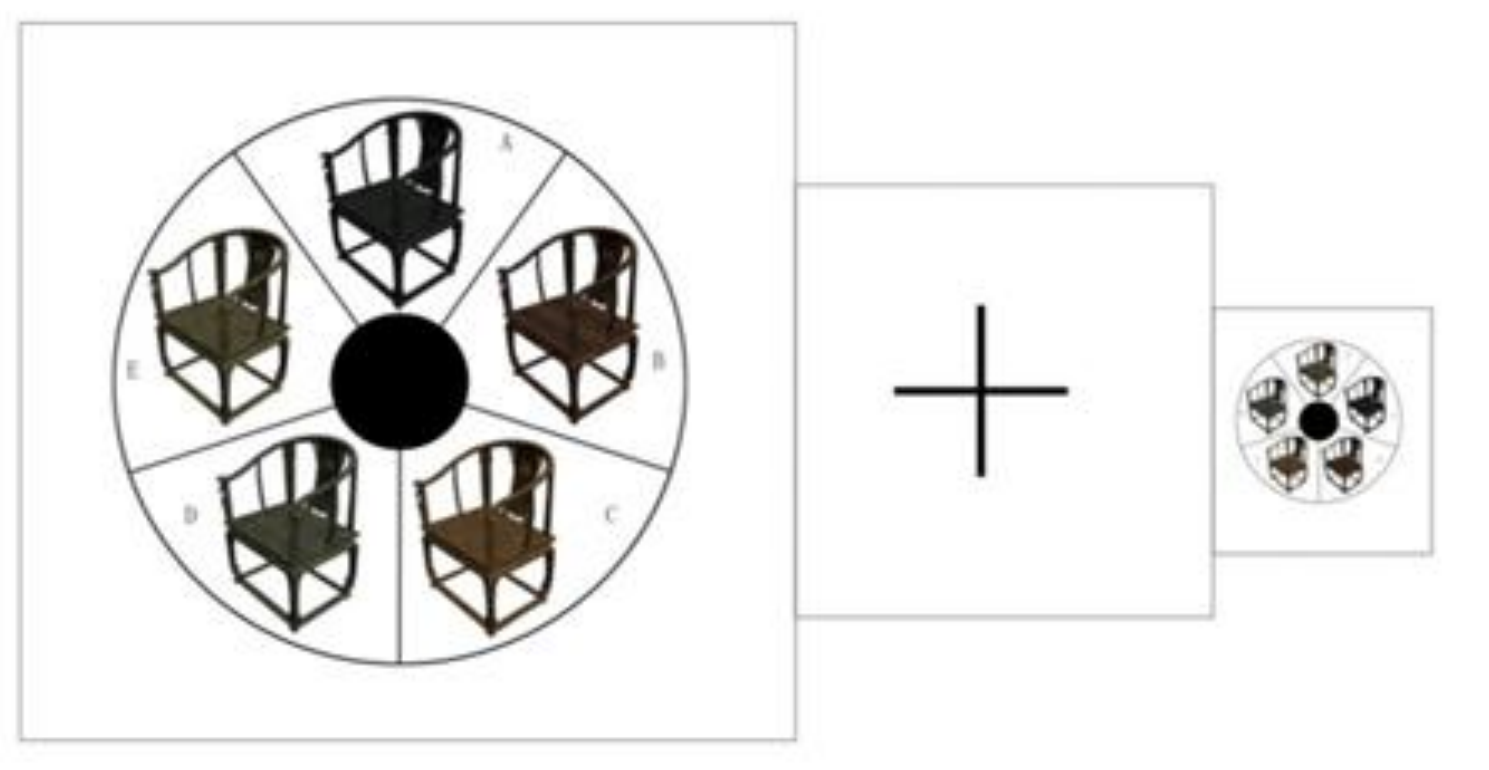

Fig. 7. Picture presentation mode 


\section{Subjective evaluation test}

This experiment was carried out after the eye movement experiment via a questionnaire. The experimental samples used in the subjective evaluation were consistent with the sample contents and placement order of the eye movement experiment. The subjects manually looked through the pictures and filled out the questionnaire. The questionnaire required the subjects to carry out subjective evaluations of the four experimental pictures separately, including a subjective evaluation of the overall preference degree for the five wood colors appearing in the picture and the subjective evaluation based on the individual characteristic score.

(1) The overall preference evaluation allowed the subject to select their favorite Sustyle chair from the five colored chairs shown in the picture and write down the letter.

(2) The subjective evaluation based on the individual feature score was to let the subject score the imagery semantic vocabulary for each type of Su-style chair. Each group of words had a score of -3 to 3 and seven grades. The subjects chose psychological scores according to their subjective feelings, e.g., -3 stood for very elegant, -2 stood for more elegant, -1 stood for slightly elegant, 0 stood for the middle of elegance and rusticity, 1 stood for slightly rustic, 2 stood for greater rusticity, and 3 stood for very rustic.

The semantic differentiation method was used. After consulting a large number of documents, two groups of perceptual lexical opposites that could be used to describe the color characteristics of fine wood were selected and made into a seven-grade scale, as shown in Table 1.

Table 1. Seven Level Scale

\begin{tabular}{|c|c|c|c|c|c|c|c|c|}
\hline & -3 & -2 & -1 & 0 & 1 & 2 & 3 & \\
\hline Elegant & $\square$ & $\square$ & $\square$ & $\square$ & $\square$ & $\square$ & $\square$ & Dark \\
\hline Light & $\square$ & $\square$ & $\square$ & $\square$ & $\square$ & $\square$ & $\square$ & $\operatorname{Dim}$ \\
\hline
\end{tabular}

Experimental data processing; Eye movement data

The obtained eye movement data was recorded in an Excel table, and the fixation time and number of fixations of each area of interest were calculated.

\section{Questionnaire Data Processing}

The questionnaire data processing was divided into two steps. First, the choice of the first question was expressed quantitatively according to what the subject chose. For example, if the subject chose A, then the A chair got a point, and if the subject chose B, then the B chair got a point. Secondly, the semantic vocabulary score was entered directly into Excel, and the average value was calculated.

\section{Significance of the six selected eye movement indexes}

An eye movement test is one of the methods to effectively determine the implicit interests of the subject. Eye movement indexes include fixations, saccades, and pupil size. There are certain links and differences between these indicators. The fixation point data was used in this experiment since fixation points are the most commonly used indicators, and specific fixation indicators have different meanings (Table 2). 
Table 2. Meaning of the Fixation Indexes

\begin{tabular}{|c|c|}
\hline Fixation Index & Meaning \\
\hline Fixation duration & $\begin{array}{l}\text { The longer the fixation duration, the more difficult it is to extract } \\
\text { information or to indicate that the target is more attractive }\end{array}$ \\
\hline Number of fixations & $\begin{array}{l}\text { The higher the number of fixations, the more important this area is } \\
\text { for the observer, and the more attention is paid to it. }\end{array}$ \\
\hline $\begin{array}{l}\text { Average fixation } \\
\text { duration }\end{array}$ & $\begin{array}{l}\text { The longer the average fixation time is, the more difficult it is to } \\
\text { extract information. }\end{array}$ \\
\hline $\begin{array}{l}\text { Number of first-sampling } \\
\text { positions }\end{array}$ & $\begin{array}{r}\text { The higher the number of first-sampling-positions, the higher the } \\
\text { degree of interest. }\end{array}$ \\
\hline $\begin{array}{l}\text { Number of last-sampling } \\
\text { positions }\end{array}$ & $\begin{array}{l}\text { The higher the number of last-sampling-positions, the higher the } \\
\text { attention. }\end{array}$ \\
\hline Fixation frequency & $\begin{array}{c}\text { The higher the fixation frequency, the higher the gaze density and } \\
\text { processing }\end{array}$ \\
\hline
\end{tabular}

\section{Judgment of Effective Eye Movement Indexes}

In this paper, the selection of the effective eye movement indexes was determined by comparing the index data of the eye movement experiment with the subjective preference score, focusing on the ranking trends of the eye movement index, the subjective evaluation, and the goodness of fit $\left(\mathrm{R}^{2}\right)$.

Correlation between the eye movement index and the subjective evaluation ranking trends

The ranking of the mean value of each eye movement index was consistent with or similar to the ranking of the subjective total preference, which indicated that the eye movement index was effective to some extent.

\section{Goodness of fit}

The correlation between the subjective total preference score and the eye movement test data was tested via regression analysis. The fitting degree $\mathrm{R}^{2}$ can explain the percentage of the data which corresponds with the linear equation to the total data. When $\mathrm{R}^{2}$ is larger than 0.6 , the equation is essentially representative of the data.

The p-value of the eye movement indexes

When the p-value of an eye movement index is less than or equal to 0.05 , there is a significant difference in the data of eye movement indexes at the $95 \%$ level of confidence; that is, when the subjects observed the Su-style chairs in different materials, the image feeling was very obvious. This indirectly shows that the data of this indicator can scientifically represent the image perception of the subjects.

\section{RESULTS AND ANALYSIS}

\section{Experimental Results and Analysis of Aesthetic Preference of Different Wood Based on Gender Difference}

According to Table 3, the p-values of the number of fixations, average fixation duration, and fixation frequency were all less than 0.01 when the subjects were observing the red sandalwood samples with different lightness values, which indicated that the three eye movement indexes were significantly different when observing the five red sandalwood chairs with different lightness values. 
Table 3. Comparisons of Gender Differences Between Different Wood Samples

\begin{tabular}{|c|c|c|c|c|c|}
\hline Wood Species & Eye Movement Index & Male & Female & $\mathrm{t}$ & $\mathrm{p}$-value \\
\hline \multirow{6}{*}{$\begin{array}{l}\text { Lightness of } \\
\text { red } \\
\text { sandalwood }\end{array}$} & Fixation duration & 6094.790 & 6716.550 & 1.492 & 0.138 \\
\hline & Number of fixations & 29.100 & 22.950 & -3.834 & 0.000 \\
\hline & $\begin{array}{c}\text { Average fixation } \\
\text { duration }\end{array}$ & 225.021 & 296.280 & 5.164 & 0.000 \\
\hline & $\begin{array}{c}\text { Number of first- } \\
\text { sampling positions }\end{array}$ & 1.000 & 1.000 & 0.000 & 1.000 \\
\hline & $\begin{array}{c}\text { Number of last- } \\
\text { sampling positions }\end{array}$ & 1.000 & 1.000 & 0.000 & 1.000 \\
\hline & Fixation frequency & 5.013 & 3.796 & -4.570 & 0.000 \\
\hline \multirow{6}{*}{$\begin{array}{l}\text { Lightness of } \\
\text { wenge wood }\end{array}$} & Fixation duration & 6328.750 & 7024.300 & 1.748 & 0.082 \\
\hline & Number of fixations & 25.950 & 23.510 & -1.611 & 0.109 \\
\hline & $\begin{array}{c}\text { Average fixation } \\
\text { duration }\end{array}$ & 249.185 & 311.969 & 4.789 & 0.000 \\
\hline & $\begin{array}{l}\text { Number of first- } \\
\text { sampling positions }\end{array}$ & 1.000 & 1.000 & 0.000 & 1.000 \\
\hline & $\begin{array}{c}\text { Number of last- } \\
\text { sampling positions }\end{array}$ & 1.000 & 1.000 & 0.000 & 1.000 \\
\hline & Fixation frequency & 4.417 & 3.558 & -3.683 & 0.000 \\
\hline \multirow{6}{*}{$\begin{array}{l}\text { Hue of red } \\
\text { sandalwood }\end{array}$} & Fixation duration & 6259.180 & 6929.700 & 1.105 & 0.271 \\
\hline & Number of fixations & 28.500 & 24.560 & -1.687 & 0.094 \\
\hline & $\begin{array}{c}\text { Average fixation } \\
\text { duration }\end{array}$ & 228.224 & 282.887 & 4.093 & 0.000 \\
\hline & $\begin{array}{c}\text { Number of first- } \\
\text { sampling positions }\end{array}$ & 1.000 & 1.000 & 0.000 & 1.000 \\
\hline & $\begin{array}{c}\text { Number of last- } \\
\text { sampling positions }\end{array}$ & 1.000 & 1.000 & 0.000 & 1.000 \\
\hline & Fixation frequency & 4.875 & 4.026 & -3.062 & 0.003 \\
\hline \multirow{13}{*}{$\begin{array}{l}\text { Hue of wenge } \\
\text { wood }\end{array}$} & Fixation duration & 6599.730 & 7276.660 & 1.415 & 0.159 \\
\hline & Number of fixations & 26.510 & 23.680 & -1.644 & 0.102 \\
\hline & $\begin{array}{c}\text { Average fixation } \\
\text { duration }\end{array}$ & 259.264 & 314.567 & 4.571 & 0.000 \\
\hline & $\begin{array}{c}\text { Number of first- } \\
\text { sampling positions }\end{array}$ & 1.000 & 1.000 & 0.000 & 1.000 \\
\hline & $\begin{array}{l}\text { Number of last- } \\
\text { sampling positions }\end{array}$ & 0.990 & 1.000 & 0.088 & 0.930 \\
\hline & Fixation frequency & 4.285 & 3.375 & -4.434 & 0.000 \\
\hline & Fixation duration & 227.754 & 291.011 & 5.364 & 0.000 \\
\hline & Number of fixations & 1.000 & 1.000 & 0.000 & 1.000 \\
\hline & $\begin{array}{c}\text { Average fixation } \\
\text { duration }\end{array}$ & 1.000 & 0.990 & -0.075 & 0.940 \\
\hline & $\begin{array}{c}\text { Number of first- } \\
\text { sampling positions }\end{array}$ & 4.880 & 3.714 & -4.888 & 0.000 \\
\hline & $\begin{array}{c}\text { Number of last- } \\
\text { sampling positions }\end{array}$ & 1.000 & 1.000 & 0.000 & 1.000 \\
\hline & Fixation frequency & 1.000 & 1.000 & 0.000 & 1.000 \\
\hline & Fixation duration & 5.274 & 4.156 & -3.601 & 0.000 \\
\hline
\end{tabular}


The p-values of the fixation duration of the first-sampling positions and lastsampling positions were all greater than 0.05 , which indicated that the three eye movement indexes had no significant difference at the $95 \%$ confidence level when observing the five red sandalwood chairs with different lightness values. The p-values of the average fixation duration and fixation frequency were all less than 0.01 when the subjects observed the five red sandalwood chairs with different lightness values, which indicated that the two eye movement indexes had significant differences when observing the five wenge wood chairs with different lightness values.

According to Table 3, the p-values of the average fixation duration and fixation frequency were all less than 0.01 when the subjects were observing the red sandalwood and wenge wood chairs with different hue values, which indicated that the two eye movement indexes had a significant difference when observing the five chairs with different hue values. The $\mathrm{p}$-values of the fixation duration, number of fixations, number of first-sampling positions, and number of last-sampling positions were all greater than 0.05 , which indicated that the four eye movement indexes had no significant difference when observing the five chairs with different lightness values.

In summary, the average fixation duration and fixation frequency had significant differences when observing the five chairs of different lightness or hue values, which indicated that these two eye movement indicators were effective eye movement indicators for the different gender aesthetic evaluation studies. When the subjects observed the Sustyle chairs of different wood types, the sex factors had a significant effect on the eye movement indexes in the modern aesthetic preference experiment.

\section{Influence of the Hue Value on Aesthetic Preference}

Results and analysis of the overall preference of two kinds of wood with different hue values

The overall preference of the subject for the five hues of red sandalwood and wenge wood were counted (the chairs selected by the subjects each got one point per selection). The overall preferences and trends for each hue chair are shown in Fig. 8.

For red sandalwood, the overall preference ranking from high to low was C, A, B, $\mathrm{D}$, and $\mathrm{E}$ (the preference scores of $\mathrm{B}$ and $\mathrm{D}$ were the same). The attention and preference of the subject did not increase with the increase in hue but showed a trend of first rising and then decreasing, whiling reaching a maximum value at a hue value of $-10(\mathrm{C})$. The subjects were the most interested in red sandalwood with a hue value of $-10(\mathrm{C})$. For wenge wood, the overall preference ranking from high to low was B, C, A, E, and D. The attention of the subject showed a decreasing trend as the hue value increased, and the subjects were the most interested in wenge wood with a hue value of $-10(\mathrm{C})$. This indicated that for these two woods, the subjects preferred a low hue in the range of -20 . 


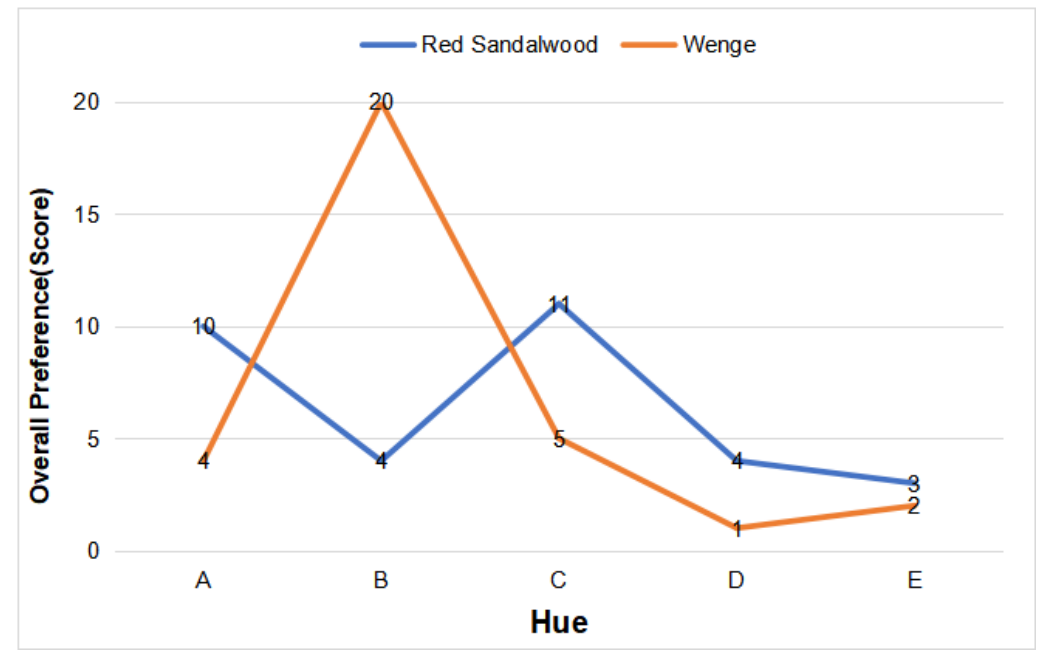

Fig. 8. Broken line diagram of the overall preferences of two types of wood

\section{Semantic Analysis Results of Different Wood Types}

According to Fig. 9, with an increase in hue, the sense of elegance and lightness also increased in the red sandalwood samples. Combined with the subjective and objective evaluations, the subjects preferred deeper and darker chairs (chair C).

According to Fig. 10, with an increase in hue, the sense of elegance and lightness also increased in the wenge wood samples. Combined with the subjective and objective evaluations, the subjects preferred more elegant and darker chairs (chair B).

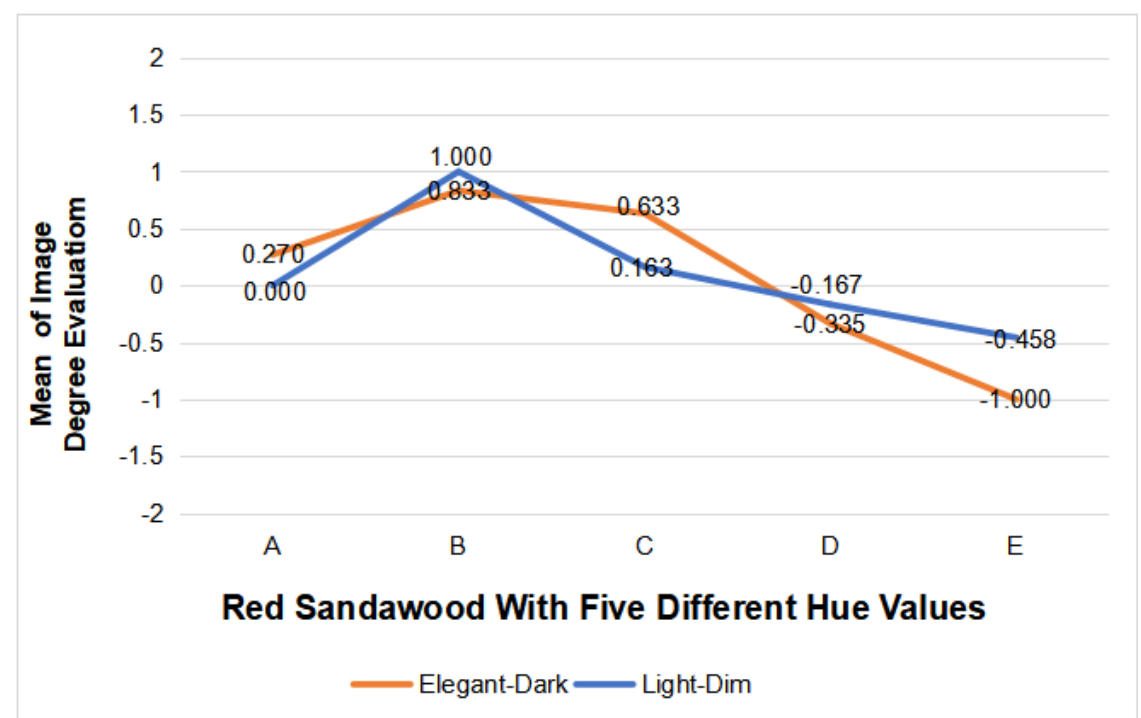

Fig. 9. Average figure of the different hue values of red sandalwood 


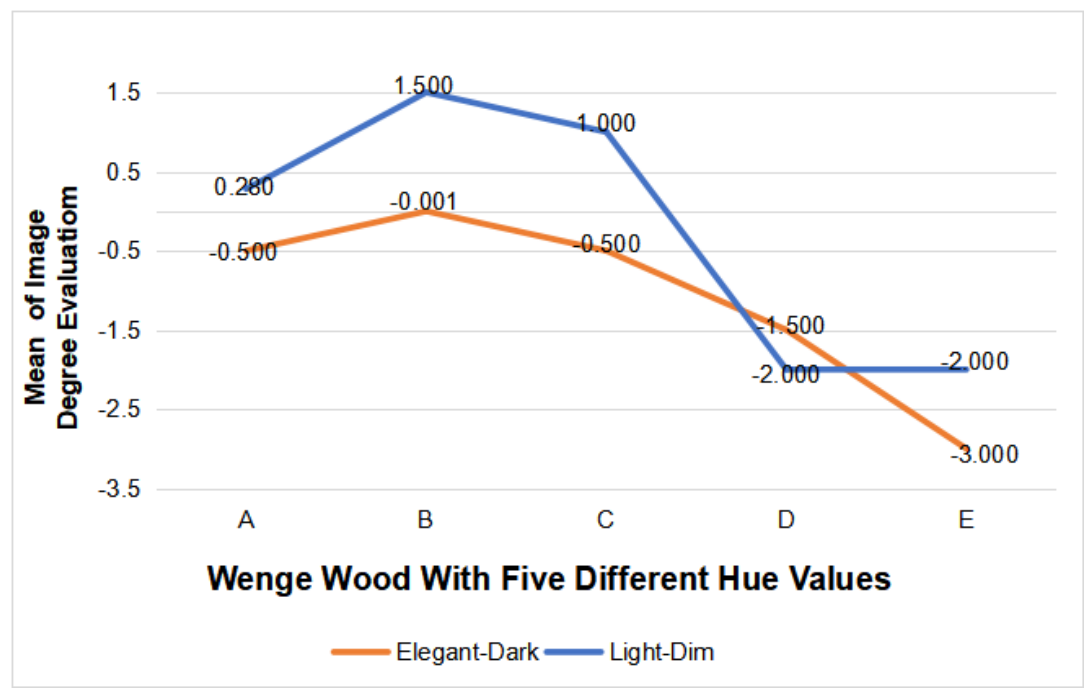

Fig. 10. Average figure of the different hue values of wenge wood.

\section{Results and Analysis of the Eye Movement Indexes}

Results of data analysis for the eye movement tests are shown in Table 4.

For red sandalwood:

(1) Correlation test analysis: The overall preferences for red sandalwood were ranked from high to low in the order of C, A, B, D, and E. According to the order of the average values of the eye movement indexes in Table 3, the fixation duration, number of fixations, and number of first-sampling positions had a certain correlation with the overall preference from the subjective evaluation, while the average fixation duration, number of last-sampling positions, and fixation frequency were not correlated with the overall preferences from the subjective evaluation.

(2) Analysis of fitting results: There was some consistency between the fixation duration, number of fixations, and number of first-sampling positions, with the subjective evaluation results, but the average fixation duration, number of last-sampling positions, and fixation frequency were not consistent with the subjective results.

(3) One-way ANOVA: The p-value of the number of first-sampling positions was less than 0.05 , which indicated that there was a significant difference in the number of firstsampling positions when the subjects observed the red sandalwood samples with different hue values, and the image feeling was obvious. The p-value of the other eye movement indexes were all greater than 0.05 , which indicated that there was no significant difference in the average fixation duration, number of last-sampling positions, and fixation frequency when the subjects observed the red sandalwood samples with different hue values, and the image feeling was not obvious.

Therefore, the effective eye movement indexes for observing different hues of red sandalwood were the fixation duration and number of fixations.

For wenge wood:

(1) Correlation test analysis: The overall preferences for wenge wood were ranked from high to low in the order of B, C, A, E, and D. According to the order of the average values of the eye movement indexes in Table 3 , the fixation duration and number of fixations had a certain correlation with the overall preference from the subjective evaluation, while the number of first-sampling positions, average fixation duration, number of last-sampling positions, and fixation frequency were not correlated with the overall 
preferences from the subjective evaluation.

(2) Analysis of fitting results: There was some consistency between the fixation duration and number of fixations with the subjective evaluation results. The number of fixations was high, while the number of first-sampling positions, average fixation duration, number of last-sampling positions, and fixation frequency were not consistent with the subjective results.

(3) Single factor analysis of variance: The p-value of the fixation duration, number of fixations, and number of first-sampling positions was less than 0.05 , which indicated that there was a significant difference in the three eye movement indexes when the subjects observed the wenge wood samples with different hue values, and the image feeling was obvious.

Therefore, the effective eye movement indexes for observing different hues of wenge wood were the fixation duration and number of fixations.

\section{Influence of the Lightness Value on the Aesthetic Preference}

Results and analysis of the overall preference of two kinds of wood of different lightness values

The overall preferences of the subjects for the five lightness values of red sandalwood and wenge wood were counted (the chair selected by the subjects got a point). The overall preferences and trends for each chair hue are shown in Fig. 11.

For red sandalwood, the overall preference ranked from high to low was C, E, D, $\mathrm{A}$, and B (the preference score was the same). The attention and preference of the subject did not increase as the lightness value increased but showed a trend of rising and then decreasing, reaching a maximum value at a lightness value of $-5(\mathrm{C})$. The subjects were more interested in red sandalwood with a lightness value of $-5(\mathrm{C})$.

For wenge wood, the overall preference ranked from high to low was A, E, B, D, and $\mathrm{C}$. The attention and preference of the subject showed a decreasing trend as the lightness value increased, and the subjects were more interested in wenge wood with a lightness value of $-10(\mathrm{C})$.

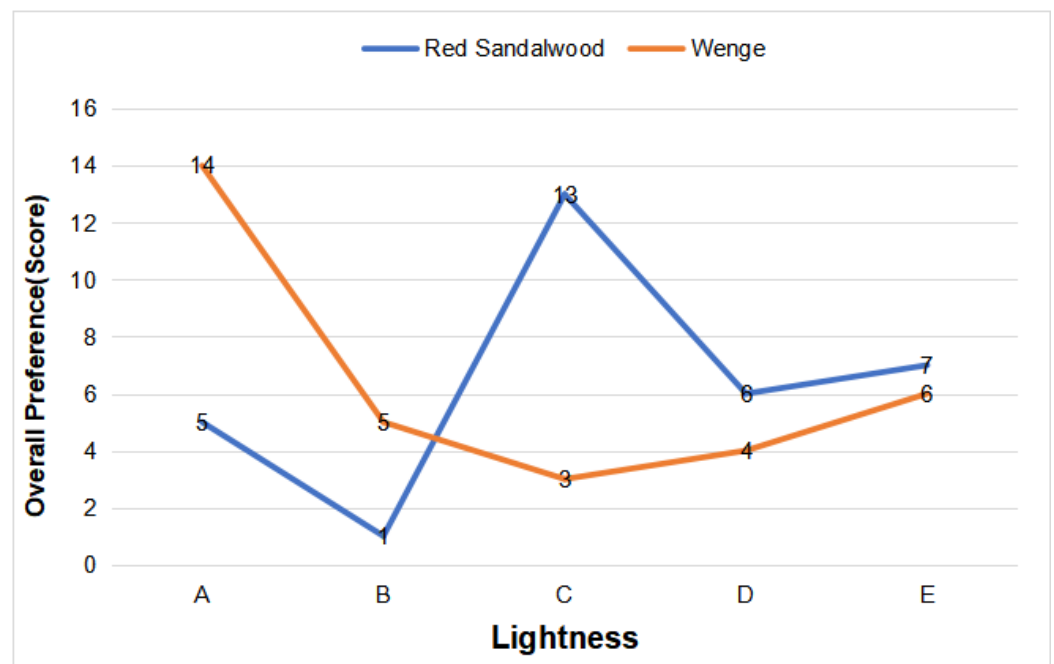

Fig. 11. Broken line diagram of the overall preferences of two types of wood 
Table 4. Single Factor Variance Analysis of Eye Movement Index and Statistical Table of Goodness of Fit for Two Kinds of Wood of Different Colors

\begin{tabular}{|c|c|c|c|c|c|c|c|c|c|}
\hline \multicolumn{2}{|c|}{ Eye Movement Indexes (mean) } & $\mathrm{A}$ & $\mathrm{B}$ & $\mathrm{C}$ & $\mathrm{D}$ & $\mathrm{E}$ & $p$-value & Regression Equation & $\mathrm{R}^{2}$ \\
\hline \multirow{2}{*}{$\begin{array}{l}\text { Fixation } \\
\text { duration }\end{array}$} & Red sandalwood & 7335.560 & 6538.060 & 7311.310 & 6442.910 & 5344.340 & 0.219 & $y=187.32 x+5395.6$ & 0.7568 \\
\hline & Wenge & 6562.470 & 9126.060 & 7445.310 & 5508.250 & 6048.880 & 0.000 & $y=172.39 x+5834.9$ & 0.8937 \\
\hline \multirow{2}{*}{$\begin{array}{c}\text { Number of } \\
\text { fixations }\end{array}$} & Red sandalwood & 28.970 & 25.910 & 30.780 & 26.500 & 20.500 & 0.064 & $y=0.881 x+20.893$ & 0.7307 \\
\hline & Wenge & 23.160 & 32.720 & 26.250 & 21.340 & 22.000 & 0.000 & $y=0.583 x+21.363$ & 0.9435 \\
\hline \multirow{2}{*}{$\begin{array}{l}\text { Average } \\
\text { fixation } \\
\text { duration }\end{array}$} & Red sandalwood & 262.114 & 268.228 & 253.123 & 243.811 & 250.503 & 0.827 & $y=0.4785 x+252.49$ & 0.0351 \\
\hline & Wenge & 291.658 & 291.419 & 299.283 & 267.290 & 284.927 & 0.590 & $y=0.6106 x+283.01$ & 0.1538 \\
\hline \multirow{2}{*}{$\begin{array}{l}\text { Number of } \\
\text { first- } \\
\text { sampling } \\
\text { position }\end{array}$} & Red sandalwood & 0.750 & 1.130 & 0.780 & 0.940 & 1.410 & 0.000 & $y=-0.0607 x+1.3907$ & 0.7045 \\
\hline & Wenge & 1.340 & 0.910 & 0.660 & 0.880 & 1.220 & 0.004 & $y=-0.0078 x+1.052$ & 0.0487 \\
\hline \multirow{2}{*}{$\begin{array}{l}\text { Number of } \\
\text { last-sampling } \\
\text { position }\end{array}$} & Red sandalwood & 0.970 & 1.030 & 1.310 & 0.970 & 0.720 & 0.320 & $y=0.0397 x+0.746$ & 0.5084 \\
\hline & Wenge & 0.690 & 1.250 & 1.190 & 0.810 & 1.030 & 0.053 & $y=0.0198 x+0.8674$ & 0.4078 \\
\hline \multirow{2}{*}{$\begin{array}{l}\text { Fixation } \\
\text { frequency }\end{array}$} & Red sandalwood & 4.225 & 4.256 & 4.490 & 4.596 & 4.685 & 0.804 & $y=-0.0229 x+4.597$ & 0.1802 \\
\hline & Wenge & 3.737 & 3.752 & 3.724 & 4.116 & 3.824 & 0.772 & $y=-0.0092 x+3.8892$ & 0.1874 \\
\hline
\end{tabular}


This indicated that for these two wood types, the subjects preferred low lightness values, i.e., in the range of -5 to 0 .

\section{Semantic Analysis of Different Wood Results}

According to Fig. 12, as the lightness value increased, the sense of elegance and lightness also increased for the red sandalwood samples. Combined with the subjective and objective evaluations, the subjects preferred deeper and darker chairs (chair C).

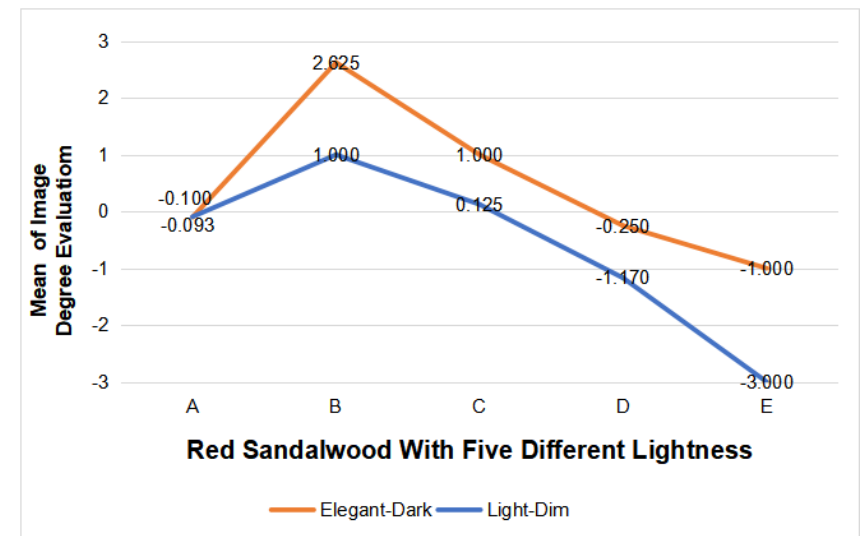

Fig. 12. Average figure of different lightness values of red sandalwood

According to Fig. 13, for wenge wood, the sense of elegance and lightness also increased as the lightness value increased. Combined with the subjective and objective evaluations, the subjects preferred more elegant and darker chairs (chair A).

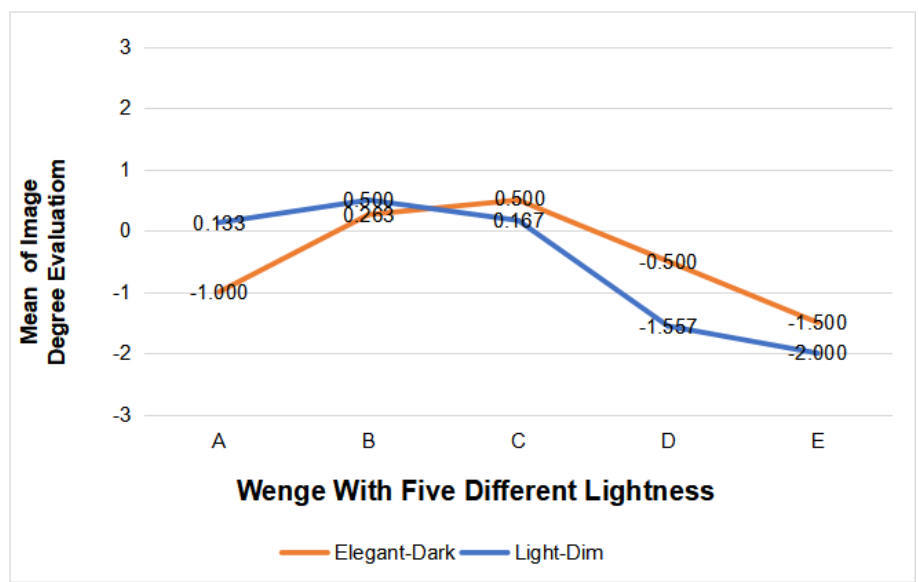

Fig. 13. Average figure of different lightness values of wenge

\section{Results and Analysis of the Eye Movement Indexes}

This paper analyzed the data of the eye movement tests, as shown in Table 5.

For red sandalwood:

(1) Correlation test analysis: The overall preferences of red sandalwood were ranked from high to low in the order of C, E, D, A, and B. According to the order of the average values of the eye movement indexes in Table 4, it can be seen that the fixation duration and number of fixations had a certain correlation with the overall preference from the subjective evaluations, while the average fixation duration, number of first-sampling 
positions, number of last-sampling positions, and fixation frequency were not correlated with the overall preference from the subjective evaluation.

(2) Analysis of fitting results: There was some consistency between the fixation duration and number of fixations with the subjective evaluation results, but the number of first-sampling positions, average fixation duration, number of last-sampling positions and fixation frequency were not consistent with the subjective results.

(3) Single factor analysis of variance: The p-values of all the eye movement indexes were all greater than 0.05 , which indicated that there was no significant difference in all the eye movement indexes when the subjects observed the red sandalwood samples of different lightness values, and the image feeling was not obvious. This showed that the subjects did not have a significant preference when observing different red sandalwood samples of different lightness values. This may be due to the lower classification levels of lightness that the subjective identification of the subject in terms of the five lightness values was not obvious, resulting in no significant bias in eye movement indexes.

Therefore, the effective eye movement indexes for observing different lightness values of red sandalwood samples were the fixation duration and number of fixations.

For wenge wood:

(1) Correlation test analysis: The overall preferences of wenge wood were ranked from high to low in the order of A, E, B, D, and C. According to the order of the average values of the eye movement indexes in Table 5, it can be seen that the fixation duration, number of fixations, and number of last-sampling positions had a certain correlation with the overall preferences from the subjective evaluation, while the average fixation duration, number of first-sampling positions, and fixation frequency were not correlated with the overall preference from the subjective evaluation.

(2) Analysis of fitting results: There was some consistency between the fixation duration, number of last-sampling positions, number of fixations with the subjective evaluation results, but the number of first-sampling positions, average fixation duration, fixation frequency were not consistent with the subjective results.

(3) Single factor analysis of variance: The p-values of all the eye movement indexes were all greater than 0.05 , which indicated that there was no significant difference in all the eye movement indexes when the subjects observed the wenge wood samples of different lightness values, and the image feeling was not obvious. This showed that the subjects did not have a significant preference when observing the wenge wood samples of different lightness values. This may be due to the lower classification level of lightness that the subjective identification of the subject in terms of the five lightness values was not obvious, resulting in no significant bias in the eye movement index.

(4) Therefore, the effective eye movement indexes for observing different lightness values of wenge wood samples were the fixation duration, number of fixations, and number of last-sampling positions. 
Table 5. Single Factor Variance Analysis of Eye Movement Index and Statistical Table of Goodness of Fit for Two Kinds of Wood of Different Lightness Values

\begin{tabular}{|c|c|c|c|c|c|c|c|c|c|}
\hline \multicolumn{2}{|c|}{ Eye Movement Indexes (mean) } & $\mathrm{A}$ & $\mathrm{B}$ & $\mathrm{C}$ & $\mathrm{D}$ & $\mathrm{E}$ & $p$-value & Regression Equation & $\mathrm{R}^{2}$ \\
\hline \multirow{2}{*}{$\begin{array}{l}\text { Fixation } \\
\text { duration }\end{array}$} & Red sandalwood & 6517.130 & 5725.380 & 6722.340 & 6469.160 & 6594.340 & 0.595 & $y=75.736 x+5921$ & 0.7012 \\
\hline & Wenge & 7272.250 & 6685.810 & 6230.060 & 6313.500 & 6881.000 & 0.463 & $y=88.367 x+6111$ & 0.8282 \\
\hline \multirow{2}{*}{$\begin{array}{l}\text { Number of } \\
\text { fixations }\end{array}$} & Red sandalwood & 26.720 & 23.880 & 28.810 & 26.090 & 24.630 & 0.376 & $y=0.374 x+23.632$ & 0.7113 \\
\hline & Wenge & 27.340 & 24.030 & 22.970 & 24.530 & 24.780 & 0.464 & $y=0.3531 x+22.47$ & 0.9218 \\
\hline \multirow{2}{*}{$\begin{array}{l}\text { Average } \\
\text { fixation } \\
\text { duration }\end{array}$} & Red sandalwood & 258.211 & 258.416 & 254.339 & 262.390 & 269.893 & 0.974 & $y=-0.2836 x+262.46$ & 0.0434 \\
\hline & Wenge & 281.652 & 282.631 & 277.590 & 264.841 & 296.170 & 0.728 & $y=0.6085 x+276.68$ & 0.0566 \\
\hline \multirow{2}{*}{$\begin{array}{l}\text { Number of } \\
\text { first- } \\
\text { sampling } \\
\text { position }\end{array}$} & Red sandalwood & 1.160 & 0.940 & 0.940 & 0.810 & 1.160 & 0.200 & $y=-0.0016 x+1.0126$ & 0.0022 \\
\hline & Wenge & 0.880 & 0.880 & 0.970 & 0.940 & 1.340 & 0.066 & $y=-0.0082 x+1.0546$ & 0.035 \\
\hline \multirow{2}{*}{$\begin{array}{l}\text { Number of } \\
\text { last-sampling } \\
\text { position }\end{array}$} & Red sandalwood & 0.780 & 1.000 & 1.030 & 0.910 & 1.280 & 0.262 & $y=0.0094 x+0.9396$ & 0.0494 \\
\hline & Wenge & 1.310 & 0.940 & 0.880 & 0.940 & 0.940 & 0.363 & $y=0.0391 x+0.752$ & 0.9715 \\
\hline \multirow{2}{*}{$\begin{array}{l}\text { Fixation } \\
\text { frequency }\end{array}$} & Red sandalwood & 4.365 & 4.523 & 4.422 & 4.435 & 4.275 & 0.988 & $y=-0.0074 x+4.4518$ & 0.1236 \\
\hline & Wenge & 3.973 & 3.907 & 4.145 & 4.218 & 3.692 & 0.678 & $y=-0.0125 x+4.0672$ & 0.0706 \\
\hline
\end{tabular}




\section{CONCLUSIONS}

The experiment was carried out via a combination of eye movement research and subjective evaluation, and the experimental results were analyzed in terms of the color aesthetic preference and lightness aesthetic preference. The experimental results can be concluded as following.

When the subjects observed Su-style chairs of different materials, sex factors had a significant effect on the eye movement indexes of the modern aesthetic preference experiment.

With different wood types, the subject preferences varied slightly but in a lower range.

Lightness group: the preferences of the subjects for these two types of wood was in a medium-to-low luminosity range. The subjects preferred the red sandalwood with a low lightness value and the wenge wood with an unchanged lightness value. The color of these two kinds of wood both had the characteristics of depth and elegance.

Hue group: The subjects preferred the color of wood with a low hue value. The subjects preferred red sandalwood with a lower hue value of brownish red, and wenge wood with the lowest hue value of dark brown, both of which had deep characteristics.

The effective eye movement indexes in this study were the fixation duration, number of fixations, and number of last-sampling positions, while the indeterminate eye movement indexes were the average fixation duration, number of first-sampling positions, and fixation frequency. In this study, there were differences in the effective eye movement indicators from the different experimental groups.

Lightness group: When the subjects observed red sandalwood, the effective eye movement indexes were fixation duration and number of fixations, while the effective eye movement indexes when the subjects observed wenge wood were the fixation duration, number of fixations, and number of last-sampling positions.

Hue group: When the subjects observed both red sandalwood and wenge wood, the effective eye movement indexes were the fixation duration and number of fixations.

Previous scholars have found a correlation between the hue value of wood and the elegant psychological quantity of the individual (Che 2009). The wood with a high lightness value gives people a sense of crispness, liveliness, and comfort; the wood with a low lightness value gives people a sense of a deep, steady, and elegant feeling (Wang 2001). This is consistent with the author's study in the fact that the preference of the subject for low lightness values and low hue values because the subject thought a low lightness and low hue values had a deeper, more elegant feeling. While the age factor and color aesthetics had a close relationship, old people preferred a darker color more than young people; therefore, research on the wood color aesthetic preferences of different age groups is necessary and feasible.

Through a combination of eye movement technology and subjective evaluation, the authors studied the aesthetic preferences for wood color, and improved the subjective description of the previously established emotional characteristics of wood colors. The quantitative analysis of the physiological data provided a more reliable research method for people to study wood color aesthetics. However, because all of the subjects were college students, it is impossible to rule out a relationship between the aesthetic preference for wood color and the age level, occupation, and other variables; thus, it is necessary to analyze and study more people of different ages groups and occupations so as to make the study as rigorous and reliable as possible. Moreover, because fine wood is difficult to 
obtain, only two kinds of wood were studied in this experiment. Future research can evaluate the color aesthetic of various furniture woods in order to establish a database of consumer preferences of different occupations and ages for modern furniture design.

\section{Conflicts for Interest}

The authors declare that there is no potential conflict interest.

\section{ACKNOWLEDGMENTS}

This project was partly supported by the National Social Fund of China (2018BH01332), the Humanities and Social Science of Ministry of Education Planning Fund (17YJCZH231), and the Project of Philosophy and Social Science Research in Colleges and Universities (2018SJA0109) in Jiangsu Province, China.

\section{REFERENCES CITED}

AL-Ayash, A., Kane, R. T., Smith, D., and Green-Armytage, P. (2016). "The influence of color on student emotion, heart rate, and performance in learning environments," Color Research \& Application 41(2), 196-205. DOI: 10.1002/col.21949

Ayama, M., Fuseda, T., Hamano, T., and Ishikawa, T. (2015). "Kansei evaluation of color images presented in color gamuts with different blue primaries," SID Symposium Digest of Technical Papers 46(1), 74-84. DOI: 10.1002/sdtp.10351

Aydemir, D., Gunduz, G., and Ozden, S. (2012). "The influence of thermal treatment on color response of wood materials," Color Research \& Application 37(2), 148-153. DOI: $10.1002 / \mathrm{col} .20655$

Brogaard, B., and Gatzia, D. E. (2017). "Is color experience cognitively penetrable?," Topics in Cognitive Science 9(1), 193-214. DOI: 10.1111/tops.12221

Broman, N. O. (2001). "Aesthetic properties in knotty wood surfaces and their connection with people's preferences," Journal of Wood Science 47(3), 192-198. DOI: $10.1007 / \mathrm{BF} 01171221$

Buratti, C., Belloni, E., Merli, F., and Ricciardi, P. (2018). "A new index combining thermal, acoustic, and visual comfort of moderate environments in temperate climates," Buildings and Environment 139, 27-37. DOI: 10.1016/j.buildenv.2018.04.038

Che, W. (2009). Research and Evaluation of Indoor Wooden Viewing Environment on Human Psychophysiological Effects, Ph.D. Dissertation, Northeast Forestry University, Harbin, China.

Choi, J., Koyama, S., Izumisawa, M., Shiragami, M., Akazawa, C., and Hibino, H. (2012). "Evaluation of users' attention to the labeling information of over-the-counter medicines using Eye-tracker," Transactions of Japan Society of Kansei Engineering 11(1), 69-78. DOI: 10.5057/jjske.11.69

Djatna, T., and Kurniati, W. D. (2015). "A system analysis and design for packaging design of powder shaped fresheners based on Kansei Engineering," Procedia Manufacturing 4, 115-123. DOI: 10.1016/j.promfg.2015.11.021

Fu, G., Wei, L. L., Cao, Y., Liu, F. T., and Li, M. L. (2016). “Optimization design of a webpage based on Kansei Engineering," Human Factors and Ergonomics in 
Manufacturing \& Service Industries 26(1), 110-126. DOI: 10.1002/hfm.20617

Fujisaki, W., Tokita, M., and Kariya, K. (2015). "Perception of the material properties of wood based on vision, audition, and touch," Vision Research 109(Part B), 185-200. DOI: $10.1016 /$ j.visres.2014.11.020

Geslin, E., Jégou, L., and Beaudoin, D. (2016). "How color properties can be used to elicit emotions in video games," International Journal of Computer Games Technology 2016(3), 1-9. DOI: 10.1155/2016/5182768

Gong, R., Wang, Q., Hai, Y., and Shao, X. (2017). "Investigation on factors to influence color emotion and color preference responses," Optik 136, 71-78. DOI:

10.1016/j.ijleo.2017.02.026

He, T., and Luo, J. (2016). "Study on the color and glossiness of 20 kinds of mahogany wood," Journal of Forestry Engineering 17(2), 44-48. DOI: 10.13360/j.issn.20961359.2016.02.008

Higa, H., Kuniyoshi, M., Dojo, T., and Nishihara, K. (2016). “A study on human interface using eye movement," IEICE Technical Report 106(370), 5-8.

Ho, M.-C., Chen, J.-M., Huang, R.-Y., Shen, M.-H., Lu, M.-C., and Liu, C.-J. (2015). "Numerical analysis on color preference and visual comfort from eye tracking technique," Mathematical Problems in Engineering 2015, 1-4. DOI:

$10.1155 / 2015 / 861610$

Hsiao, S.-W., and Yang, M.-H. (2016). "A methodology for predicting the color trend to get a three-colored combination," Color Research \& Application 42(1), 102-114. DOI: $10.1002 / \operatorname{col} .22046$

Hsu, C.-C., Fann, S.-C., and Chuang, M.-C. (2017). "Relationship between eye fixation patterns and Kansei evaluation of 3D chair forms," Displays 50, 21-34. DOI: 10.1016/j.displa.2017.09.002

Jia, T.-Y., and Niu, X.-T. (2017). "Evaluation of color and visual properties of 22 kinds of redwood," Journal of Northwest Forestry University 32(6), 250-258+269.

Kearney, G. E. (1966). "Hue preferences as a function of ambient temperatures," Australian Journal of Psychology 18(3), 271-275. DOI: 10.1080/00049536608255549

Köhler, M., Falk, B., and Schmitt, R. (2014). "Applying eye-tracking in Kansei engineering method for design evaluations in product development," International Journal of Affective Engineering 14(3), 241-251. DOI: 10.5057/ijae.IJAE-D-1500016

Korsavi, S. S., Zomorodian, Z. S., and Tahsildoost, M. (2016). "Visual comfort assessment of daylit and sunlit areas: A longitudinal field survey in classrooms in Kashan, Iran," Energy and Buildings 128, 305-318. DOI: 10.1016/j.enbuild.2016.06.091

Liu, Y., Li, J., Guo, M., Yu, J., and Wang, Y. (1995). “The distribution characteristics of visual physical quantities on wood surface of 110 tree species in China," Journal of Northeast Forestry University 1995(1), 52-58.

Liu, S., Lin, J., Lin, Y., Ke, L., and Hu, J. (2013). "Analysis of surface characteristics of four kinds of commonly used decoration and decoration wood," Journal of Fujian Forestry Science and Technology 2013(3), 54-56.

Liu, M., Sun, D., and Chen, X. (2015). "Study on aesthetic preference of different wardrobe door panel materials based on eye movement analysis," China Forest Product Industry 2015(5), 27-30.

Liu, X. Y., Timar, M. C., Varodi, A. M., and Sawyer, G. (2017). “An investigation of 
accelerated temperature-induced ageing of four wood species: Colour and FTIR," Wood Science and Technology 51(2), 357-378. DOI: 10.1007/s00226-016-0867-4

Liu, F., and Kang, J. (2018). "Relationship between street scale and subjective assessment of audio-visual environment comfort based on 3D virtual reality and dualchannel acoustic tests," Building and Environment 129, 35-45. DOI:

10.1016/j.buildenv.2017.11.040

Mamassian, P. (2016). "Sensory plasticity: When eye movements change visual appearance," Current Biology 26(1), 24-26. DOI: 10.1016/j.cub.2015.11.008

Manav, B. (2017). "Color emotion associations, designing color schemes for urban environment-architectural settings," Color Research \& Application 42(5), 631-640. DOI: $10.1002 /$ col.22123

Mirijovsky, J., and Popelka, S. (2016). "Evaluation of color settings in aerial images with the use of eye-tracking user study," in: The Proceedings of the International Archives of the Photogrammetry, Remote Sensing and Spatial Information Sciences, 12-19 July, Prague, Czech Republic, pp. 763-767.

Muslim, E., Nurtjahyo, B., and Dewi A. A. (2013). "Analysis of the effectiveness of kompas newspaper advertising in term of size and color factors using eye tracking method," in: International Conference on Quality in Research, Yogyakarta, Indonesia, pp. 241-251.

Reinprecht, L., Mamoňová, M., Pánek, M., and Kačík, F. (2018). “The impact of natural and artificial weathering on the visual, colour and structural changes of seven tropical woods," European Journal of Wood and Wood Products 76, 175-190. DOI: 10.1007/s00107-017-1228-1

Shamey, R., Sawatwarakul, W., and Fu, S. (2015). "Does hue affect the perception of grayness?," Color Research \& Application 40(4), 374-382. DOI: 10.1002/col.21894

Shieh, M.-D., and Yeh, Y.-E. (2015). "A comparative study on perceptual evaluations of sports shoe exterior colors in Taiwan," Color Research \& Application 40(2), 178-193. DOI: $10.1002 / \mathrm{col} .21870$

Stone, N. J., and English, A. J. (1998). "Task type, posters and workspace color on mood, satisfaction, and performance," Journal of Environmental Psychology 18(2), 175-185. DOI: 10.1006/jevp.1998.0084

Sutton, T. M., and Altarriba, J. (2016). "Color associations to emotion and emotion-laden words: A collection of norms for stimulus construction and selection," Behavior Research Methods 48(2), 686-728. DOI: 10.3758/s13428-015-0598-8

Lee, T.-R., Tang, D.-L., and Tsai, C.-M. (2013). "Exploring color preference through eye tracking," in: The Proceedings of the AIC Colour 05-10 ${ }^{\text {th }}$ Congress of the International Colour Association, 8-13 May, Granada, Spain, pp. 333-336.

Tama, I. P., Azlia, W., and Hardiningtyas, D. (2015). "Development of customer oriented product design using Kansei Engineering and Kano Model: Case study of ceramic souvenir," Procedia Manufacturing 4, 328-335. DOI: 10.1016/j.promfg.2015.11.048

Timar, M. C., Varodi, A. M., and Garău, L. (2016). "Comparative study of photo degradation of six wood species after short time UV exposure," Wood Science and Technology 50(1), 135-163. DOI: 10.1007/s00226-015-0771-3

Varodi, A. M., Timar, M. C., You, L. X., and Colocariu, C. (2017). "Effect of natural ageing in indoors conditions on the colour of wood surface finished with natural traditional materials," Pro Ligno 13(4), 331-340.

Vieira, J., Osório, J. M. A., Mouta, S., Delgado, P., Portinha, A., Meireles, J. F., and Santos, J. A. (2017). "Kansei engineering as a tool for the design of in-vehicle rubber 
keypads," Applied Ergonomics 61(1), 1-11. DOI: 10.1016/j.apergo.2016.12.019

Wang, Q., Song, S. S., Li, X. H., Zhang, Q., Yang, X., Zhang, Y. C., Fei, B. H., and Yao, L. (2018). "The visual perception of the cardboard product using eye-tracking technology," Wood Research 63(1), 165-178.

Wang, W.-B. (2001). The Measurement of Visual Physical Quantity of 103 Kinds of Furniture Surface Color and the Analysis of the Characteristics of Color Psychology, $\mathrm{Ph} . \mathrm{D}$. Dissertation, Northeast Forestry University, Harbin, China.

Yang, Z., Liu, Y. N., and Lv, B. (2012). "Rapid assessment of surface color of Chinese fir and eucalyptus wood by near infrared spectroscopy," Applied Mechanics \& Materials 157-158, 304-307. DOI: 10.4028/www.scientific.net/AMM.157-158.304

Xing, Y., and Qiang, W. (2009). "Advertisement effect evaluation system based on face detection and tracking," Journal of Computer Applications 29(10), 2700-2702. DOI: 10.3724/SP.J.1087.2009.02700

Zhang, Y., Zhang, S. Y., and Chui, Y. H. (2010). "Impact of melt impregnation on the color of wood-plastic composites," Journal of Applied Polymer Science 102(3), 21492157. DOI: $10.1002 / a p p .24161$

Article submitted: October 7, 2020; Peer review completed: March 20, 2021; Revised version received and accepted: April 17, 2021; Published: April 26, 2021.

DOI: $10.15376 /$ biores.16.2.4126-4148 